\title{
Reconciliación y construcción de la categoría víctima: Implicaciones para la acción política en Chile
}

\author{
Reconciliation and construction of the victim category: \\ Implications for political action in Chile
}

\author{
Marisela Montenegro M. ${ }^{1}$ \\ Isabel Piper S. ${ }^{2}$
}

\section{Resumen}

Los procesos de reconciliación nacional a partir del reconocimiento de la violación de los Derechos Humanos han sido puestos en práctica para fortalecer las democracias actuales. En este artículo nos centraremos en el caso chileno y sus intentos de avanzar en el proceso de reconciliación post-dictadura militar (1973-1990), a partir del establecimiento de la verdad sobre las formas de violencia perpetradas. La idea de reconciliación sigue la lógica de la retórica de la marca; esto es, el argumento de que las victimas han quedado marcadas a partir de la experiencia traumática perpetrada. En este proceso se ha constituido la categoría de víctima y su reparación como el centro del proceso de reconciliación.

La categoría de víctima ha sido utilizada como eje articulador de las luchas en torno a los Derechos Humanos. Sin embargo, ha contribuido a fijar dichas identidades como esenciales, naturales y homogéneas entre sí. En este artículo pretendemos cuestionar dicha construcción para, por un lado, mostrar su carácter contingente y en constante redefinición y, por otro, contribuir a abrir otros espacios de acción política en el Chile actual.

Palabras clave: reconciliación, reparación, víctimas, identidad, política, Chile.

Doctora en Psicología Social. Universidad Autónoma de Barcelona. España.

selabarna@gmail.com

Doctora en Psicología Social. Universidad Autónoma de Barcelona. Académica Departamento de Psicología. Universidad de Chile. Santiago, Chile. ipiper@uchile.cl 


\section{Abstract}

The processes of national reconciliation grounded on the acknowledgment of the violation of Human Rights have been accomplished in different countries in order to strengthen the current democracies. In this article we will focus on the Chilean case, which, in recent history, has attempted to move forward in the process of post-dictatorship reconciliation.

The idea of reconciliation follows the logic of the rhetoric of branding; that is, it is sustained on the argument that the victims have been left branded after the traumatic experience perpetrated against them. In this process, the constitution of victim category and the consequent reparation are at the center of the process of reconciliation.

The victim category has been used as the articulating axis of the struggles around the issue of Human Rights. Nevertheless, this process has helped to fix such identity in an essential, natural and homogeneous way. In this article we intend to question this construction in order to, on one hand, show its contingent character and its constant redefinition process; and on the other, contribute to opening up other spaces of political action in Chile today.

Key words: Reconciliation, reparation, victims, identity, politics, Chile. 


\section{Introducción}

Diversas investigaciones han mostrado la fuerza que la dictadura militar chilena de Pinochet (1973-1990) tiene en las memorias colectivas de dicha sociedad (Castillo y Piper, 1998; Joignant, 2007; Lira y Morales, 2005; Piper, 2005). La preocupación por el impacto que la violencia ocurrida en esos años tuvo sobre quienes vivieron directamente la represión política sigue presente en las reflexiones sobre Derechos Humanos, sobre la participación política de los chilenos, la re-construcción de la democracia, y otros temas en los cuales la vinculación entre los ámbitos inter-subjetivos y políticos es insoslayable.

En este artículo se analizará la lógica en torno a la cual se ha desarrollado el proceso de reconciliación en Chile y el discurso de los Derechos Humanos en el que se sostiene. Se hará referencia a las nociones de reconciliación, trauma político y reparación en tanto elementos inseparables de un mismo proceso. El conjunto de prácticas y nociones implicadas contribuye a configurar una escena psico-política compleja en la cual se generan diversos procesos especialmente relevantes para la Psicología Política.

El presente análisis se centrará en las consecuencias, en términos políticos, de la lógica de los procesos de reconciliación en Chile. En primer lugar, se enmarcará la discusión en las actuales formas de entender los procesos de reconciliación, bajo la tríada conceptual reconciliación/ trauma-político/reparación. En segundo lugar, se argumentará que dicho proceso se sostiene sobre una lógica a la que se ha llamado retórica de la marca (Piper, 2005). Entre las consecuencias de esta retórica está la contribución a construir, a partir de sus experiencias del pasado, categorías de sujetos excluyentes como lo son la de víctimas y no-víctimas.

Posteriormente se focalizará la discusión en las consecuencias en términos políticos de la construcción del sujeto víctima, analizando las posibilidades y límites que se pueden desprender para la acción política en la actualidad. Se reflexionará en torno a los efectos de los movimientos identitarios en relación con la construcción de la categoría de víctima de 
las violaciones a los Derechos Humanos. A partir de ello se argumentará que, aunque hay muchas formas de ser victima, en Chile la polisemia de identidades se suele reducir a la vivencia del cuerpo dañado por la violencia, excluyéndose las posibles articulaciones transversales con otros movimientos políticos basados en otras categorías de sujeto y otras agencias de transformación social. Se profundizará en el tema a través del análisis de los efectos de los discursos de Derechos Humanos en Chile.

\section{Los discursos de Derechos Humanos en Chile y la tríada: daño- reparación-reconciliación}

Los discursos de Derechos Humanos en Chile se han organizado en la última década en torno a tres ideas centrales o convicciones compartidas por amplios sectores sociales.

La primera de ellas es que la violencia represiva de la dictadura tuvo un efecto negativo sobre la sociedad chilena en general, y sobre los grupos y personas que la vivieron directamente en particular. La Psicología Política ha contribuido de manera importante a las reflexiones sobre dicho daño desarrollando la noción de trauma político (con sus diversos matices y acepciones) y articulando intervenciones orientadas a enfrentarlo. La polarización de la sociedad en bandos contrapuestos es entendida como efecto de la violencia política y como parte del proceso de traumatización (ILAS, 1991; ILAS, 1994).

Un segundo elemento de articulación de los discursos de Derechos Humanos es la convicción de que dicho daño o trauma debe ser reparado y que ello permitiría a la sociedad chilena reconciliarse. La reconciliación de los grupos contrapuestos es vista como requisito necesario para construir una convivencia pacífica que garantice la estabilidad democrática. Si dicha polarización es producto del daño, entonces la reparación sería un paso necesario para que la reconciliación sea posible.

El tercer elemento se refiere a la necesidad de reconstruir las memorias de las víctimas para que la reparación (y por tanto la reconciliación) pueda llevarse a cabo. Es decir, el trauma producido por la dictadura sólo podrá ser elaborado cuando la sociedad asuma la verdad de lo ocurrido 
y reconstruya su historia en base a los acontecimientos silenciados por el poder militar.

La transición del gobierno militar al gobierno civil se enfrentó desde el principio (y aún se enfrenta) con las demandas de las agrupaciones de victimas y defensores de los Derechos Humanos, que giran en torno a la justicia, la verdad y la reparación. También se enfrentó con la necesidad ética y política de abordar, de alguna manera, el legado de las violaciones a los Derechos Humanos.

Elizabeth Lira lo dice así:

"el reconocimiento de este problema implica poner en palabras una memoria traumática que ha sido la verdad de las víctimas de manera que pueda ser una verdad de la sociedad. Se trata de recuperar la memoria del horror y del miedo, de la persecución y de la muerte" (Lira, 1997, p. 135).

Para ello se han establecido, entre otras medidas, la constitución de comisiones encargadas de investigar lo ocurrido y de establecer una verdad compartida, una memoria común de los hechos. Chile ha tenido dos Comisiones de Verdad: la Comisión Nacional de Verdad y Reconciliación y la Comisión Nacional sobre Prisión Política y Tortura.

La Comisión Rettig (nombre con el que es comúnmente conocida la Comisión Nacional de Verdad y Reconciliación) investigó durante 1990 y 1991 las violaciones a los derechos humanos acaecidas en Chile durante la dictadura militar de Augusto Pinochet, específicamente la desaparición de personas, su ejecución o torturas con resultado de muerte. En sus nueve meses de trabajo la Comisión recibió 3.550 denuncias, de las cuales 2.296 fueron consideradas como casos calificados, es decir, como víctimas de la violencia política o violaciones a los Derechos Humanos (Comisión de Verdad y Reconciliación, 1991).

La Comisión Valech (nombre con el que es comúnmente conocida la Comisión Nacional sobre Prisión Política y Tortura) investigó durante el 2003 y 2004 las detenciones y torturas por razones políticas ocurridas durante la dictadura militar. Su objetivo era suplir las carencias de la Comisión Rettig, que sólo investigó los casos de desaparición o 
muerte, sin calificar como victimas a quienes sufrieron la prisión política y la sobrevivieron. Al final del proceso fueron reconocidas como víctimas de prisión política y tortura 28.459 personas (Comisión Nacional sobre Prisión Política y Tortura, 2004).

Ambas Comisiones elaboraron un informe final en el que se establece una versión común y consensuada que toma en cuenta las diversas versiones de los hechos ocurridos. Dichos informes son producto de investigaciones exhaustivas, realizadas por cuerpos de expertos en el tema, que son considerados ecuánimes (personajes socialmente respetados de los distintos sectores políticos). Los informes establecen una nueva verdad oficial en base a las memorias de los distintos sectores implicados en el conflicto. En ella se reconoce no sólo la versión que los afectados tienen del pasado violento, sino también su calidad de víctima. El objetivo de ello es sentar las bases para que dichos sectores se reconcilien y así evitar que la violencia vuelva a instalarse.

"El conocimiento del dolor vivido y del daño producido, puesto de manifiesto en la búsqueda y el establecimiento de la verdad, ha conducido a la rehabilitación del nombre de quienes lo sufrieron de manera directa y ya no están. Al mismo tiempo, permite reparar, en la medida que es posible, los efectos sobre las familias y los deudos de estas víctimas" (Corporación Nacional de Reparación y Reconciliación, 1996, p. 8).

La tarea de recoger testimonios y calificar como víctima de las violaciones a los Derechos Humanos o Víctima de la Violencia Política (es decir, otorgar la calidad de tal) es una tarea de dichas comisiones.

"Cada víctima ha sido reconocida bajo esa inspiración y representa el reconocimiento del valor de una persona en su dignidad esencial y en los derechos que de ésta emanan, afirmando su identidad individual y trascendente. Esta verdad ha inspirado el gesto concreto del acto reparatorio por parte de la sociedad hacia su familia, como un signo efectivo de la voluntad de reconciliación" (Corporación Nacional de Reparación y Reconciliación, 1996, p. 8). 
Ambas asumen que las violaciones a los Derechos Humanos ocurridas durante la dictadura provocaron un daño en quienes la sufrieron (daño al que llaman trauma). El informe Rettig enfatiza la necesidad de identificar a las víctimas y de otorgarles atención especializada que permita reparar dichos daños.

"Desde el punto de vista de la salud hemos recibido significativas opiniones. Ellas tienden a señalar su preocupación por la salud de los familiares de las víctimas y a recomendar que se les otorgue una atención especial, en vista de las consecuencias que los actos violatorios han provocado en su salud (...). Se trata de daños manifiestos o que están todavía latentes en la población, los que según los especialistas serán difíciles de superar en el corto plazo, ya que pueden alcanzar hasta la tercera generación. Cualquiera sea su magnitud, las opiniones especializadas que ha recibido esta Comisión estiman que se trata de un problema muy importante en términos cualitativos, consistente en una traumatización extrema" (Comisión Nacional de Verdad y Reconciliación, 1991, p. 830).

Argumentando lo mismo, aunque esta vez refiriéndose a las consecuencias de la detención y la tortura en sus víctimas, el Informe Valech señala:

"La tortura ha sido conceptualizada como una experiencia traumática que ha provocado consecuencias sistémicas. (...) Dadas estas características, se puede afirmar que las condiciones de prisión política y tortura descritas en este Informe violaron los Derechos de las personas, causándoles daños emocionales, morales y materiales, que ameritan un proceso de reparación integral. Para ello es preciso no sólo reconocer la ocurrencia de los hechos en general y la responsabilidad del Estado en particular, sino identificar también a cada persona que fue víctima de sus agentes, estableciendo su derecho de una reparación justa y digna" (Comisión Nacional Sobre Prisión Política y Tortura, 2004, p. 513). 
Las medidas de reparación propuestas por las comisiones de verdad se tradujeron en una ley y en un conjunto de políticas sociales específicas dirigidas a las víctimas. Éstas contemplan indemnizaciones económicas, becas de estudio, atención gratuita y especializada en salud, entre otras. Un ejemplo de ello es la creación en 1991 del programa PRAIS (Programa de Reparación y Atención Integral en Salud a las familias más severamente afectadas por la represión política). Para la implementación de la ley de reparación (Ley 19.123, aprobada en el año 1990) fue indispensable definir y delimitar a quién se considera víctima de violaciones a los Derechos Humanos. Eso es algo que hizo en primera instancia la Comisión de Verdad y Reconciliación (1991) y que luego se completó en la Comisión Nacional sobre Prisión Política y Tortura (2004).

La preocupación por la reparación y la reconciliación son señales de la opción que hacen los gobiernos de transición por una justicia restaurativa (en lugar de una restitutiva) como un camino preferido para la consecución de la paz.

La justicia restaurativa, según Humphrey (2005), busca compensar los efectos de la violencia a través de la implementación de estrategias que promuevan la elaboración del daño. La elección del camino terapéutico de la reconciliación es percibida como menos amenazante que el camino legal (Humphrey, 2005).

Lo anterior muestra cómo los procesos de reparación y reconciliación se dan a partir de decisiones de carácter político, en los que las maneras de entender y actuar la reconciliación se definen y redefinen en un marco concreto de acción.

\section{Reconciliación: La construcción de un concepto y una práctica}

Las referencias a la noción de reconciliación son habituales en los periodos en los que la unidad de un país se ve amenazada, por ejemplo por una guerra civil o una dictadura militar donde se han violado sistemáticamente los Derechos Humanos. En términos generales, reconciliación se refiere a la búsqueda de la unidad perdida por medio de la aceptación de ciertas reglas de gobernabilidad (Juricic y Reyes, 2000). Sin embargo, 
es necesario profundizar en dicho concepto que implica y genera diversas definiciones de sujetos y categorías.

Según Staub (2006), reconciliación se refiere a un proceso en el que victimas y perpetradores (o miembros de grupos hostiles) aceptan al otro con el fin de generar relaciones constructivas. Dichas relaciones deben restaurar, de un modo u otro, el daño producido por las relaciones violentas del pasado e inaugurar el futuro en términos diferentes a los que, hasta ese momento, se dieron. Rehabilitar el daño causado, entonces, está en el centro de la idea de reconciliación que dicho autor desarrolla, pues sin ella el diálogo entre diferentes grupos sería imposible. La reparación de la experiencia traumática tendría efectos terapéuticos, ya que modera la percepción del mundo como un lugar peligroso y hace más probable cambios positivos entre sectores sociales previamente enfrentados.

Por su parte, para Govier y Verwoerd (2002), la reconciliación involucra la construcción y reconstrucción de las relaciones sociales sobre la base de la confianza. Ésta es entendida como una actitud general entre las partes oponentes que protege a los involucrados. Es decir, el establecimiento de una relación de confianza mutua permite que los grupos opuestos no sufran daño. Para estos autores, la reparación es el proceso de construcción de espacios de confianza en las relaciones que han sido dañadas por la violencia.

En ambas nociones de reconciliación es posible observar cómo se construye una oposición entre grupos sociales amplios. Por un lado están aquellos que han perpetrado algún tipo de violencia y, por otro, los que son catalogados como víctimas de los primeros. El ejercicio de la violencia produce un daño en las víctimas que debe ser reparado para que ambas partes puedan reconciliarse. Esta reconciliación debe darse a través de relaciones de confianza a partir de las cuales sea posible construir un futuro en el que no se repitan las relaciones violentas causantes de todo el proceso.

En la llamada vía chilena de la reconciliación (Lira y Loveman, 1999a) es posible encontrar la práctica de estas nociones. Para ello se establece como primer paso la búsqueda de una versión compartida del pasado donde se legitime la experiencia, hasta el momento negada, de las víctimas. 
Sin embargo, el establecimiento de una versión común y consensuada de los acontecimientos se ve dificultada por la emergencia de las diferencias, de los posicionamientos antagónicos y extremos, en definitiva, de memorias contrapuestas que significan el pasado de manera radicalmente distinta. Dicha polarización de la sociedad en posturas antagónicas es percibida por los gobiernos de transición a la democracia como una amenaza. El mantener el conflicto vigente se entiende como un peligro para la estabilidad del país y la consolidación de las instituciones democráticas (Juricic y Reyes, 2000).

Por tanto, aunque el contexto postdictatorial posibilita la emergencia de diferencias, se opta por la búsqueda de la reconciliación como una manera de enfrentarlas y resolverlas. Para construir las relaciones de confianza mutua se opta por apelar a lo común. En palabras de Reyes, "a conformar un 'nosotros' por sobre las diferencias” (Juricic y Reyes, 2000).

La reconciliación aparece así como la búsqueda de encuentro entre bandos contrapuestos con el fin de asegurar la gobernabilidad. En este proceso lo principal radica en hacer desaparecer las diferencias con el propósito de lograr y mantener una ilusión de armonía (Moulian, 1997; Lira y Loveman, 1999a; 1999b).

$\mathrm{Si}$, siguiendo a Doxtader (2003), entendemos el concepto de reconciliación a partir de una lectura retórica, podemos ver cómo éste surge en un contexto determinado y genera, en su nombrar, los propios elementos que nombra. Entender la reconciliación como una práctica retórica supone preguntarse por aquello que productivamente construye y reconstruye el propio campo en el cual es dicho y actuado. Así, en la historia, los procesos de reconciliación conforman una retórica hecha memoria, un recuerdo activo que construye realidades, sujetos, relaciones y políticas.

Es en este sentido que proponemos analizar los procesos de reconciliación en Chile a partir del análisis de sus consecuencias políticas. Para ello profundizaremos en las lógicas argumentativas de las nociones de reparación y reconciliación hasta ahora expuestas, mostrando cómo se articulan en torno a lo que se ha llamado una retórica de la marca (Piper, 2005). 
La retórica de la marca inaugura los procesos de reconciliación a través de la conformación de un sujeto, la víctima. Se trata de un sujeto marcado por el daño, traumatizado por la violencia. La reconciliación, así, parte de la definición de un sujeto marcado que debe ser reparado por el daño que se le ha infligido con el fin de generar un campo donde sea posible transformar las relaciones de violencia en actitudes de confianza, hacia la construcción de la paz.

\section{La reconciliación y la retórica de la marca}

$\mathrm{Al}$ narrar los acontecimientos de la historia reciente de Chile, los discursos de Derechos Humanos se refieren al golpe militar de 1973 y los 17 años de dictadura como los años que marcaron al país. El día del golpe se constituye en estas memorias en el día de la marca, el momento en que finaliza una etapa y comienzan los años de violencia que habrían dejado sus huellas en la sociedad chilena.

"En la memoria colectiva de los chilenos, la imagen del comienzo de la dictadura se retrata en aquel martes 11 de septiembre de 1973, con La Moneda bombardeada y en llamas. Es la imagen de un triunfo aplastante para unos, o de una tremenda y dramática derrota para los otros. El marcador que separa un antes y un después que lo cruza y cercena todo" (Amaro, 2004, p. 41).

En sus análisis de las memorias que los chilenos construyen de la dictadura militar, Piper (2005) muestra cómo dichos discursos la señalan como el evento que divide la historia del país introduciendo una fractura que la separa en un antes y un después. La violencia de la dictadura habría implicado un quiebre de tal magnitud que ni las personas que la vivieron directamente, ni sus familias, ni la sociedad en su conjunto habrían vuelto a ser los mismos de antes. Entre los legados de la dictadura estaría la división de la sociedad en bandos contrapuestos y la constitución de un nuevo sujeto social: las víctimas de las violaciones a los Derechos Humanos.

Así, en primer lugar, los procesos de reconciliación del pasado reciente y del presente chileno descansan sobre un discurso de un país 
marcado por acontecimientos violentos que fracturaron la sociedad y que generaron un contexto de enfrentamiento de intereses entre grupos diversos.

De esta manera, las narraciones sobre lo ocurrido en Chile van construyendo a la dictadura y su violencia como un conjunto de experiencias que dejó sus huellas, su cicatriz, su marca, en definitiva, que dañó o traumatizó a la sociedad. Son muy diversos los sectores sociales que comparten la convicción de que tanto la sociedad chilena como las victimas directas fueron afectadas negativamente por la violencia de la dictadura militar. La idea de la historia fracturada por la violencia es usada para explicar procesos sociales e individuales y, como se ha dicho, para enmarcar los procesos de reconciliación nacional.

Se va configurando así una retórica para la cual la dictadura opera como causa de lo que son tanto los individuos como la sociedad. Dicho de otra manera, las identidades sociales y personales son producidas en el discurso como consecuencia directa de haber vivido la dictadura, la que continuaría presente a través de sus marcas.

La convicción de que la dictadura opera como un accidente que marcó y transformó las identidades aplica para diversos niveles, uno de ellos es el de los y las afectados/as directos/as, cuyas historias personales e identidades habrían sido interrumpidas dando inicio a una nueva vida marcada por la experiencia de ser víctima. Los discursos construyen un sujeto nacido de las experiencias traumáticas, cuyo presente estaría constituido por los legados del pasado.

Entonces, en segundo lugar, los procesos de reconciliación se justifican a partir de la construcción del sujeto víctima, que es producido en el discurso como aquel que ha sufrido directamente la violencia política.

El Informe de la Comisión Nacional de Verdad y Reconciliación (1991) se refiere a dichos sujetos de la siguiente manera:

"La tensión permanente a que han estado sometidas estas personas las ha hecho más vulnerables. En el ámbito de la salud mental presentan graves sintomatologías. Se trata de experiencias traumáticas, que por su calidad y magnitud no alcanzan a ser procesadas y asimiladas por la estructura psíquica 
de las personas. En consecuencia, todos sus intentos posteriores de reorganización quedarán marcados por el daño infligido, a menos que reciban ayuda especializada" (Comisión Nacional de Verdad y Reconciliación, 1991, p. 831).

El Informe de la Comisión Nacional sobre Prisión Política y Tortura (2004), en su capítulo sobre las consecuencias de dicha experiencia, afirma que:

"De acuerdo al testimonio de miles de personas que declararon ante esta Comisión a lo largo de todo el país, la experiencia de la prisión política y la tortura representó un quiebre vital que cruzó todas las dimensiones de la existencia de las víctimas y sus familias. En muchos casos, las huellas de esa experiencia traumática les acompañan hasta el presente" (Comisión Nacional sobre Prisión Política y Tortura, 2004, p. 29).

Los discursos de Derechos Humanos argumentan (en la lógica de la retórica de la marca) que las historias e identidades de quienes vivieron directamente la violencia de la dictadura fueron interrumpidas dando inicio a una nueva vida marcada por la experiencia de ser víctima. El sufrimiento que dicha vivencia implica les habría llevado a ocupar un lugar en la sociedad distinto al que se ocupaba antes y distinto de quienes no la han vivido.

Los informes señalan que el daño no es algo del pasado sino que es plenamente actual. El dolor dejado por las huellas de la violencia se habría instalado en la vida cotidiana, marcando la manera de relacionarse con el mundo. Se habla de haber sido dañado de por vida, de nunca haber podido volver a sentirse normal, dejando poco espacio a la posibilidad de revertir el daño.

"Por todo lo que tuve que vivir, he quedado con un trauma psicológico irreparable y $\mathrm{mi}$ sistema nervioso totalmente destruido, hasta el día de hoy" (Comisión Nacional sobre Prisión Política y Tortura, 2004, p. 603).

La retórica de la marca produce por esta vía la categoría de víctima: un sujeto dańado y marcado por la experiencia violenta vivida en 
el pasado. Se trata de un sujeto traumatizado en el proceso de violencia que lo transformó en víctima.

Buscando desarrollar un concepto que dé cuenta del daño producido por las violaciones a los Derechos Humanos, la psicología ha usado términos tales como trauma político; trauma psicosocial; traumatización extrema, entre otros. Éstos hacen referencia a uno o más acontecimiento/s socio-político/s que dañan profundamente a quien lo vive, dejando profundas marcas (Bettelheim, 1981; Keilson, 1979; Lira y Piper, 1996; Martín-Baró, 1990).

El supuesto que asume las distintas nociones de trauma es común y se ha instalado en los discursos de Derechos Humanos. Se asume que las historias de vida de cada una de las personas que sufrieron la violencia política debía seguir un proceso evolutivo normal a partir de una coherencia interna que prometía mantenerse. Sin embargo, este trayecto habría sido interrumpido por la experiencia de la dictadura que quebró la estabilidad y la promesa, transformando a estas personas en nuevos sujetos traumatizados. La víctima es, entonces, un sujeto dañado por las prácticas de violencia represiva.

Según los discursos de Derechos Humanos, los traumas o huellas dejados por las experiencias del pasado tendrían que ser reparados, es decir, las marcas tendrían que ser borradas para permitir que la sociedad volviera a su normalidad. La idea es sencilla y clara. La sociedad chilena está herida y debe curarse; está rota y debe re-armarse, despejando, en la medida de lo posible, los escombros dejados por el pasado.

Un tercer aspecto del proceso de reconciliación es, entonces, su relación indisoluble con los procesos de reparación. La reconciliación se basa, entre otras cosas, en el reconocimiento de la experiencia traumática que marcó a las víctimas y a la sociedad; un reconocimiento público de dicha marca, de esa experiencia traumática que da paso a la posibilidad de reconciliación de la sociedad (Schaap, 2004).

Es decir, para que la sociedad pueda reconciliarse y para que el daño pueda repararse es indispensable que ella reconozca la existencia del nuevo sujeto social en su seno, la víctima de la violencia política. 
Ambos procesos implican una suerte de vuelta a la normalidad. ¿Cómo es esa normalidad? Los discursos no explicitan eso, pero sí suponen la existencia de un estado anterior al conflicto que habría que recuperar para asegurar la estabilidad política y la paz social.

La idea de re-conciliar supone que antes de la división de la sociedad en bandos opuestos existía un estado de conciliación. No se trata de negar el conflicto, sino de retenerlo en un ámbito restringido, controlable, manejable para la política institucional. Esto se logra deponiendo las diferencias en pos de recuperar un supuesto pasado mítico de unión y comunidad que habría sido roto por la violencia. La acción política se orienta hacia la recuperación de dicho pasado que, como sostiene Reyes, es "incorpóreo, intemporal, pasado al que sólo se le utiliza para dar cuenta de que aquella reconciliación es posible en su realización, es deseable y esperable" (Reyes, 2003, p. 18).

La reparación supone un proceso de elaboración mediante el cual las heridas dejadas por la violencia sean sanadas y sus cicatrices borradas. Se trata no de eliminar lo sucedido, sino de incorporar la experiencia traumática en una identidad continua no fracturada. Mediante el reconocimiento de las violaciones de Derechos Humanos ocurridas se busca resolver sus consecuencias en los individuos y en la sociedad; es decir, reparar el daño, borrar la marca, y si esto no es posible, por lo menos mitigar la intensidad de sus efectos (Lira y Morales, 2005; Staub, 2006). Se pone en marcha el proceso de justicia restaurativa (Humphrey, 2005) en la que el Estado terapéutico distribuye los recursos necesarios para esta reparación.

Trauma, reparación y reconciliación son, entonces, los ejes centrales de la retórica de la marca, según la cual las heridas dejadas por la violencia deben ser sanadas y sus cicatrices curadas. Ello permitiría asegurar una convivencia pacífica, en la cual las diferencias sean controladas para que los hechos de la dictadura no vuelvan a repetirse.

En síntesis, la lógica de la retórica de la marca, base del proceso de reconciliación en Chile, sería la siguiente: la violencia de la dictadura constituyó un quiebre, una fractura que dejó la marca de su daño en individuos y sociedad. Esta marca opera como núcleo articulador de 
identidades sociales e individuales. La retórica de la marca produce la categoría de víctima, un sujeto dañado y marcado por la experiencia violenta vivida en el pasado. Es deber del Estado reparar el daño. A través de sus instituciones, éste debe revelar la verdad de lo ocurrido y disponer recursos para la reparación de aquellos sujetos traumatizados por la violencia.

\section{La categoría víctima como identidad}

Como hemos visto hasta ahora, entre los efectos de la retórica de la marca está el contribuir a construir un sujeto social: la víctima. El haber sufrido algún tipo de experiencia represiva se constituye en uno de los puntos de partida para la construcción del sentido de la experiencia. Los discursos de la dictadura suponen que haber vivido directamente su violencia opera como un universal de significación sobre el cual se articula la experiencia de la diferencia entre sujetos, es decir, que haber sufrido la represión funciona como sentido configurador de la identidad. Las marcas de la violencia actúan como núcleo de articulación entre sus víctimas, quienes se reconocen entre sí por la experiencia común de saberse marcados. Aunque hay múltiples formas de ser víctima (no es lo mismo haber sido exonerado del trabajo que tener un familiar muerto o desaparecido), la polisemia de identidades confluye en una forma común de la experiencia, que se construye en oposición a quienes no sufrieron la represión política.

Sin embargo, la definición de víctima y, por ende, de las personas que deben ser reparadas a través de los recursos del Estado, como representante de la sociedad, es un asunto abierto a debate político. Tal como afirma Reicher (2004), no hay ninguna forma de categorización social dada por sentado. No hay categorías sociales que se mantengan a través de todos los contextos, ya que los procesos de categorización social están entrelazados con la organización de la acción y el contexto en el que surgen.

En el caso de Chile, según Humphrey (2005), la Comisión Nacional de Verdad y Reconciliación produjo una jerarquía de prestigio entre las víctimas de los abusos a los Derechos Humanos. En la más alta jerarquía estaban aquellas personas entendidas como inocentes, las familias 
de desaparecidos por ejemplo, mientras que en la parte más baja estarían aquellos implicados en actividades de violencia política contra el Estado, los prisioneros políticos torturados. Después de más de una década de publicado aquel informe tuvo resultado la demanda de los prisioneros políticos para que dichas situaciones fueran investigadas desde el Estado.

El estatus de víctima, en los procesos de reconciliación en Chile, se ha transformado en algo importante a alcanzar en la medida en que implica un reconocimiento social de su existencia como sujeto (marcado). Podría pensarse que la importancia de adquirir dicho estatus estaría dada por la posibilidad de acceder a los beneficios que establecen las leyes de reparación. Sin embargo, su análisis en tanto discursos identitarios permite sostener que su importancia trasciende dicha posibilidad, y que lo que estaría en juego es el reconocimiento de una supuesta esencia personal y social que constituye a este sujeto víctima. Un ejemplo de ello se puede encontrar en el llamado que, desde principios del 2005, está haciendo la autodenominada Agrupación de Ex- Menores de Edad Víctimas de Prisión Política y Tortura (2005a). Se trata de personas que, siendo menores de edad, fueron víctimas de prisión y tortura o que estaban en gestación cuando sus madres fueron detenidas. Dicha agrupación se constituye con el fin de demandar un reconocimiento formal de su calidad de víctima, y los beneficios concretos que por tanto le corresponderían. Pero su reivindicación no es sólo material: exigen que su experiencia sea entendida como traumática en sí misma, es decir, sostienen que no es suficiente ser considerados hijos de víctimas, pues eso no da cuenta de una identidad a la que sienten que tienen por derecho propio. "Exigimos, como sobrevivientes del terrorismo de Estado, nuestro derecho a ser reconocidos como víctimas directas de tortura y prisión política" (Agrupación de Ex-Menores de Edad Víctimas de Prisión Política y Tortura [2005b]).

Las distintas agrupaciones de afectados/as no han dejado de demandar su derecho a ser considerados/as víctimas y poder, por tanto, acceder a ser reparados/as por el Estado, ya que las luchas por el reconocimiento son la base de los términos en los que se realiza la asociación política (Schaap, 2004). 
La categoría de víctima, por tanto, está en constante construcción y reconstrucción a través del debate abierto sobre quién debe ser considerado como tal y quién no, lo cual tiene tanto consecuencias en los recursos destinados para la reparación como en la configuración de agentes sociales relevantes para tener voz en las demandas hacia el Estado y la dirección de los procesos de reconciliación nacional.

Así, la propia constitución del sujeto víctima se constituye como un campo político de controversia entre instituciones, movimientos sociales, investigadores, políticos y otros agentes sociales. La víctima se constituye como el centro de la reconciliación, pues son el vehículo de dicho proceso en las políticas de la verdad y en el foco de la reparación.

La identidad de víctima ha funcionado como eje articulador de diversos procesos sociales, lo que la ha transformado en el eje central de ellos. Ha sido usada como categoría de diagnóstico psicológico, así como de lugar argumentativo que explica las más diversas características y problemas de la vida cotidiana. También opera como elemento conformador de movimientos sociales identitarios que basan su resistencia a la dictadura y a sus regímenes posteriores en dicha identidad. Las agrupaciones de victimas se han organizado en torno a sus respectivos apellidos, es decir, los familiares de detenidos desaparecidos y los de ejecutados políticos; los exonerados; los exiliados y posteriormente los retornados; los ex-presos políticos, etc., que defienden, la relación de identidad para llevar adelante sus resistencias y proyectos políticos transformadores. Aunque la defensa de la identidad de víctima ha cumplido en ciertos contextos políticos una función estratégica, argumentamos que en el Chile postdictadura ha ido más allá de eso, conformando una categoría esencialista y acarreando con ello diversas consecuencias.

\section{La politización de la identidad: La víctima como articulador de luchas identitarias}

Aunque la categoría de víctima está sujeta a una politización constante, las luchas políticas a su alrededor se basan en una idea de 
sufrimiento común entre quienes conforman la categoría, una marca que identifica al sujeto que la ha sufrido. Las demandas acerca de políticas de recuperación de la memoria y de reparación se hacen a partir de la alusión a ese sufrimiento común. Las marcas dejadas por la violencia se transforman en una característica de quienes vivieron dicha experiencia. Ésta se torna esencial en la medida en que se asume, por un lado, que es una característica imborrable y permanente, y por otro, en que se sostiene como necesario que las personas que han sufrido la experiencia de violencia sean conscientes de su condición de víctima para poder elaborar el daño que les ha sido causado.

La esencialización de la categoría de víctima, a través de la unificación de las diversas experiencias de violencia sufridas, tiene un efecto de reafirmación del carácter dañado del sujeto, dificultando, al mismo tiempo, su liberación. Los sujetos, en este caso las víctimas, aparecen en el discurso como un dato, un hecho objetivo. Esta operación, a su vez, genera un efecto de objetivación, o incluso de naturalización, que no es posible sino por prácticas semióticas y materiales concretas que precisamente intentan ocultar su propio funcionamiento al mostrar al sujeto como sustancia fijada al margen de cualquier práctica de significación y como origen de éstas, no como su consecuencia (Ema, 2006).

Las críticas que se hacen actualmente desde posturas feministas (Mohanty, 2003; Mouffe, 1992) y de estudios culturales (Ahmed, 1996; Spivak, 1999) a la esencialización de las categorías identitarias y al uso de ellas en las luchas políticas, aluden a los efectos perversos que pueden producir las categorías ligadas a una identidad -como por ejemplo las referidas al género, a las opciones sexuales no hegemónicas o al uso de la cultura como articulador identitario- (Grupo de trabajo Queer, 2005). Extrapolando estas discusiones al uso de la categoría de víctima, podemos observar que se generan los mismos efectos perversos que aquellos que se derivan del uso de otras categorías identitarias, también entendidas como esenciales (como el género o el origen cultural).

El uso de una identidad como articuladora en las luchas sociales contiene un efecto de homogeneización de la propia categoría (Ahmed, 
1996; Butler, 1993). Se produce una fijación en la que todas las personas catalogadas como pertenecientes a la categoría en cuestión quedan envueltas en una misma definición (Ema, 2006). Así, se construye un sujeto fuerte que se articula alrededor de dicha identidad y que erige, en el caso que nos ocupa, un imaginario del sujeto víctima produciendo una articulación de sentidos en el cual todas las experiencias y secuelas de la violencia se convierten en la misma, operando como si todas las individualidades que están bajo esa misma categoría fueran idénticas entre sí. La universalización y totalización que se hace de esta categoría al contraponerla a la de novíctima obvia las diferencias de cada una de las experiencias.

El sujeto víctima, además, se representa a través de las organizaciones legitimadas para tal fin: agrupaciones de victimas que son portavoces de los mensajes institucionales que se quieren hacer llegar a la sociedad más amplia. Tal como afirma Reicher (2004), las diversas dimensiones sociales de los procesos de identificación y los objetivos de la acción colectiva están dados a partir de los presupuestos del grupo específico en términos de identidad. Por tanto, la legitimidad de esa voz viene dada, precisamente, al originarse en ese sujeto fuerte que ha sufrido y que está marcado por las consecuencias de la violencia y, por tanto, es quien puede dar cuenta de su experiencia y de las consecuencias de ésta.

Entre los efectos de este mecanismo está, por un lado, que se subsume la voz de todas las víctimas en una sola -aquella que funciona como portavoz de la categoría- y, por otro, que se deslegitima la inclusión de cualquier otra voz - proveniente de personas incluidas en la categoría de no-victimas - en el debate relativo a las experiencias de violencia acaecidas.

La fijación social de la posición y voz de las víctimas en organizaciones que las representan trae consigo la institucionalización del movimiento. Siguiendo a Melucci (1996), el Estado crea estructuras para reducir la diversidad y agregar a las personas en categorías, con el fin de desarrollar sistemas para relacionarse con los movimientos sociales, y poder dar respuesta a sus demandas. Así la institucionalización del movimiento es una consecuencia de este proceso de inclusión, lo cual trae consigo la pérdida, en cierto sentido, de su carácter crítico al estar ya pautada dentro 
del juego institucional. La apertura de espacios para la creación de otras formas de memoria o de reconstrucción del pasado, del presente o del futuro, tiene poca cabida si no proviene de los espacios sociales legitimados para tal fin a partir del sujeto construido como marcado. Como consecuencia, la inclusión de temas de debate en la reflexión desde el presente se hace mucho más difícil.

Por otro lado, la organización social basada en la exclusividad de la pertenencia a la categoría de víctima para la acción política hace muy difícil que los movimientos de defensa de los Derechos Humanos se articulen con movimientos políticos de transformación basados en otras categorías de sujeto u otras reivindicaciones concretas. Aunque hay asociaciones que han funcionado, por ejemplo entre feministas y movimientos de Derechos Humanos, en ellas (al menos en la historia reciente de Chile) ha primado la defensa de la categoría de víctima de la represión política. En este movimiento, la injusticia es reconceptualizada como daño psicológico que apela a una retórica emotiva del ser y del trauma invocado como auténtico sufrimiento, lo cual valida argumentos políticos, sociales y morales. Así, a través de la construcción de la categoría de víctima, se ha adoptado, por parte del Estado y del movimiento de víctimas, una política de la emocionalidad como una nueva fuente de legitimación (Pupavac, 2004).

La experiencia violenta que hace que surja la categoría de víctima es resignificada en cada acto político, reproduciendo una retórica que deja la acción política y reivindicativa en la demanda de reparación de la experiencia pasada, reivindicación que deja inalterado el juego de categorías identitarias y posibilidades políticas ya establecidas e institucionalizadas. Un ejemplo de ello son las conmemoraciones del 11 de Septiembre (Fernández, 2005; Joignant, 2007).

Así, lo propiamente político de los procesos de reconciliación estaría dado, por un lado, por los procesos de definición de quién es definido como víctima y como no-víctima y, por otro, por situar la respuesta política frente a la violencia pasada en un cuerpo político que debe ser reparado, una armonía original que al ser restaurada podrá dar las condiciones de vivir en paz (Schaap, 2004). El foco en la salud y la reparación de las 
victimas hace que la definición de la violencia y, por tanto, la cuestión de los derechos desaparezcan de las narrativas relativas a la reconciliación, poniendo el foco en los efectos de la violencia en lugar de las causas de ésta (Humphrey, 2005).

\section{Construcción y reconstrucción de identidades: un asunto político}

"Para iniciar la reconciliación entre antiguos enemigos se debe predicar una política del reconocimiento en términos de identidad y otredad de acuerdo a las cuales los errores pasados fueron perpetrados. Sin embargo, en la medida en que dicha política es retomada como un bien social, corre el riesgo de solidificar y reificar las maneras en las que las partes se entienden a sí mismas que la reconciliación política debe cuestionar" (Schaap, 2004, p. 534) ${ }^{3}$.

Sin embargo, una política de la reconciliación debe ser predicada a partir de tomar en cuenta la contingencia y revisabilidad del nosotros que la sostiene. Ya que es, precisamente, la contingencia y fragilidad de ese nosotros la condición de posibilidad de dicha reconciliación (Christodoulidis, 2003).

De esta manera, la aseveración de una categoría esencial es necesaria para establecer los lazos de solidaridad entre las victimas que pueda construir las bases de la acción colectiva. Sin embargo, dicha categoría resulta restrictiva, en términos de la apertura a nuevas formas de acción política también necesarias en los procesos de reconciliación.

La crítica de la categoría de víctima, entonces, aparece como una tarea aún pendiente en los procesos de reconciliación en Chile. Para esto proponemos dar algunas pinceladas a las tradiciones que en las ciencias sociales han inspirado formas alternativas de pensar las nociones de sujeto

\footnotetext{
3 "In order to initiate reconciliation between former enemies, a politics of recognition must be predicated within the terms of identity and otherness according to which past wrongs were perpetrated. Yet, to the extent that such a politics takes these identities as irreducibly social goods, it risks entrenching and reifying those self-understandings that political reconciliation ought to call into question" (Schaap, 2004. p. 534).
} 
y de identidad. Vamos a referirnos brevemente a algunos elementos de dichas tradiciones que permiten entender las memorias de la dictadura como tecnologías de las cuales emergen múltiples posiciones de sujeto, que actualmente resultan en la construcción del sujeto víctima.

Un principio común a las críticas antiesencialistas provenientes de tradiciones tales como la hermenéutica de Gadamer (1991), la filosofía del lenguaje inspirada en Wittgenstein (1987), el pragmatismo norteamericano, así como en Lacan (1977), Derrida (1989) y/o Foucault (1992; 1997), es la oposición a la idea de una naturaleza universal del ser humano y el abandono de la categoría de sujeto como una entidad racional transparente y homogénea. Tomando en cuenta estos desarrollos, Mouffe (1992) afirma que la historia del sujeto es la historia de sus identificaciones y que no hay una identidad oculta a ser rescatada más allá de aquéllas; esto es, no hay una sustancia que subyace a las identificaciones de los sujetos y que represente su verdadero ser.

Mouffe (1999) propone un doble movimiento: por un lado, un movimiento de descentramiento del sujeto que previene de la fijación de un conjunto de posiciones alrededor de un punto preconstituido; y, por otro, el movimiento opuesto, la institución de puntos nodales que permiten articulaciones en torno a fijaciones precarias y dinámicas de significados desde los cuales se puede acceder a una pluralidad de prácticas políticas. Ella concluye que la deconstrucción de las identidades esenciales debe ser vista como una condición necesaria y adecuada para entender la variedad de relaciones sociales donde los principios de libertad e igualdad deben aplicarse.

Estas propuestas son resumidas por Amigot de la siguiente manera: "El análisis postestructuralista permite entender instancias que han sido sustancializadas y concebidas como ontológicamente preexistentes a su estudio, intenta comprenderlas en un marco relacional en el que sus fronteras y límites se desdibujan, se vuelven porosos, se desvanecen. El individuo, la sociedad y el conocimiento que en ella se produce están íntimamente conectados: el individuo está condicionado en su desarrollo por el tejido social 
de prácticas, relaciones y símbolos en el que se inserta y que remite siempre a un momento histórico y a una sociedad determinada" (Amigot, 2005, p. 94).

En este sentido, desde las críticas provenientes de diferentes marcos teóricos, se entiende que la formación del sujeto está situada sociohistóricamente y en un entramado de operaciones de construcción que permiten pensarlo a partir de los vínculos que lo constituyen. Las identidades que en un momento histórico toman relevancia son, pues, generadas a partir de operaciones de inclusión y exclusión en las que se constituyen los contornos de qué significa estar en una categoría (Butler, 1993). Como hemos visto, la categoría de víctima de violación de los Derechos Humanos, en el caso de Chile, ha seguido una serie de operaciones de definición -a través de discursos públicos, servicios de atención para ellas, formas de simbolización, etc.- que delimitan quién puede estar, o quién no, bajo el epígrafe de dicha categoría. Estos procesos de definición son complejos y crean efectos de verdad y consecuencias en las vidas de las personas que están situadas en las diferentes categorías que se generan (víctima-no-víctima).

Por su parte, Donna Haraway (1995), para expresar la fragmentación e incompletitud de cualquier identidad, utiliza la metáfora de los cyborgs (criaturas ficcionales y reales a la vez) la cual refiere a la hibridez y parcialidad de las posiciones de sujeto. La parcialidad presenta la posibilidad de la conexión con otros/as, de la polifonía y de las definiciones perecederas o simultáneamente contradictorias, desde las cuales es posible conectar. Sujetos parciales, posiciones específicas, cyborgs, se conectan produciendo límites y definiciones de sí mismos, de otros/as y del mundo. Así, lo colectivo se convierte en un artefacto social-relacional, en el que conviven y conectan actores diversos (Haraway, 1999).

Las perspectivas trabajadas se refieren a los mecanismos de constitución del sujeto, y lo conciben como un conjunto de posiciones construidas en el seno de relaciones de inclusión/exclusión, discursos y prácticas en las que se crean sus límites. A la vez, las posiciones-sujeto pueden ser ocupadas en ciertas condiciones por distintos individuos, aunque el ejercicio de ese espacio nunca será realizado de la misma manera (Mouffe, 1992). 


\section{Aperturas para la acción política en el presente}

Tomar como referencia las ideas de dichas autoras en el análisis de las memorias de la dictadura nos permite problematizar la existencia de un núcleo identitario propio del sujeto víctima centrándonos en los mecanismos políticos que lo constituyen. Es el ejercicio mismo de la violencia el que genera diversas posiciones de sujeto que se definen mutuamente en relaciones de significación mutua. Pero no se trata sólo de la oposición víctima/victimario sino también de todos aquellos límites y movimientos que separan a quien forma parte de esa dupla de quien ocupa un lugar de exterioridad, es decir, quien se define (y es definido) como no-víctima.

Pero un elemento significativo de las posturas de Butler (1993), Mouffe (1992) y Haraway (1999) es que permiten pensar al sujeto y a sus asociaciones como coaliciones temporales, lo que Laclau y Mouffe (1985) llaman bloque histórico. Con dicho concepto se refieren a alianzas entre elementos fragmentarios que se fijan sólo a partir de sus articulaciones, y que crean espacios sociales y políticos relativamente unificados que se construyen como antagónicos a otros espacios y que adquieren su significado en contextos y relaciones específicas. La ausencia de una esencia identitaria y de una unidad dada de antemano no impide la construcción de múltiples formas de asociación donde individuos, grupos, organizaciones, etc., están localizados de maneras similares con relación a discursos particulares, y consecuentemente, a acciones comunes. Ciertas coaliciones pueden surgir como resultado de la construcción de puntos nodales: formas de unidad que pueden dar lugar a maneras precarias de identificación. El concepto de bloque histórico muestra que la fragmentación, incompletitud y pluralidad de identidades emergentes no necesariamente significa una pérdida de capacidad política; más bien puede ampliar caminos hacia nuevas formas de luchas que puedan crear condiciones que sean más difíciles de manipulación y control. $\mathrm{O}$ tal como afirma Ema:

"Deconstruir al sujeto de la política; es decir, mostrar su naturaleza no dada, no definitiva y no natural, no es el final de la política; 
sino precisamente su principio, su condición de posibilidad. En la medida en que el sujeto moderno que era considerado como fundamento ya no es tal, quedan abiertos los procesos de constitución de órdenes sociales y de producción de subjetividades como proceso conflictivo y político en un campo marcado por la ausencia de fundamentos últimos" (Ema, 2006, p. 174).

No se trata, entonces, de negar la existencia de un sujeto víctima, sino de asumir su carácter de construcción histórica, y de entender sus fijaciones como resultados temporales hegemónicos, estabilizaciones de poder que implican siempre ciertas exclusiones. Se trata de problematizar los límites y significados de las categorías de sujetos prefigurados que acceden a la acción política, justamente por el carácter político de las acciones de articulación.

Una vez que se acepta que el sujeto víctima está constituido en redes de relaciones de poder, es necesario pensar en sus posibilidades de agencia y transformación en el ámbito de las acciones políticas. También es necesario, siguiendo a Butler (1997), preguntarse cuáles son las condiciones de posibilidad de su agencia, así como de reconfigurar la matriz de poder en la cual estamos constituidos/as o las posibilidades de regulación que puedan desestabilizar los regímenes de poder existentes. Cuestionar la fijación de la categoría de víctima y sus identidades permite abrirse a ese tipo de cuestiones redefiniendo el rango de posibilidades de articulación para acciones políticas de transformación social.

Cuando entendemos a los sujetos sociales y sus problemas del presente como una producción permanente de las formas de relacionarnos, pierden importancia las huellas del pasado, y se hacen visibles las prácticas actuales de dominación. La retórica de la marca contribuye a generar la convicción de que hay esencias (personales y sociales) que han sido fracturadas o trastornadas (traumatizadas) por las acciones represivas de la dictadura, lo que desperfila el carácter constructor de relaciones sociales de nuestras acciones.

Hemos mostrado la necesidad teórica y política de criticar la idea de que tenemos una subjetividad personal y colectiva que fue dañada, 
entendiendo cómo nuestras prácticas sociales construyen una forma de ser personal y social, y cómo nuestras memorias de la dictadura construyen sujetos que sostienen la precariedad democrática en la que vivimos.

El sujeto víctima se ve a sí mismo/a y es visto por otros/as como un sujeto con atributos especiales y, al categorizar y estigmatizar a quienes los poseen, confirma la normalidad de aquel sujeto no-víctima o normal. Es decir, el atributo de dańado o traumatizado de este sujeto lo convierte en un sujeto desviado de la norma, o sea, alguien que se aparta negativamente de las expectativas particulares que están en discusión.

Finalmente, la respuesta terapéutica que proponen los procesos de reconciliación en Chile asume que para lograr la reconciliación es necesaria la reparación psicológica y social de las víctimas. Esto invisibiliza la lucha política de definición de la propia categoría y, además, desvía el conflicto hacia las consecuencias de la violencia y no hacia sus causas. En este sentido, produce un cierre sobre las posibles construcciones de la memoria y sobre la consecución de procesos de reconciliación basados en la administración de la justicia, poniendo el acento en los elementos del pasado y no en el futuro a construir.

\section{Referencias bibliográficas}

AgRUPACIÓN DE EX-MENORES DE EDAD VÍCTIMAS DE PRISIÓN POLÍTICA Y TORTURA. (2005a). Extraído el 11 de octubre de 2006 desde http://www.lashistoriasquepodemoscontar.cl/chicos.htm

AgrupaCión DE EX-MENORES DE EDAD VÍCTIMAS DE PRISIÓN POLÍTICA Y TORTURA. (2005b). Extraído el 21 de noviembre de 2006 desde http://trincheradelaimagen.blogspot.com/2005/09/ex-menoresvictimas-de-represion.htlm

Ahmed, S. (1996). Moving spaces. Black feminism and post-colonial theory. Theory, culture and society, 13, $139-146$.

Amaro, R. (2004). Los caminos de la resistencia a la dictadura. Colección Nosotros los chilenos, 6, 28-57. 
Amigot, P. (2005). Relaciones de poder, espacio subjetivo y prácticas de libertad: Análisis genealógico de un proceso de transformación de género. Tesis de Doctorado no publicada, Universidad Autónoma de Barcelona.

Bettelheim, B. (1981). Sobrevivir: El holocausto una generación después. Barcelona: Crítica.

Butler, J. (1993). Bodies that matter. On the discursive limits of "sex". New York: Routledge.

Butler, J. (1997). Contingent foundations: Feminism and the question of 'postmodernism'. In J. Butler \& J. Scott (Eds.) Feminist Theorize The Political. New York: Routledge.

Castillo, I. y Piper, I. (2007). (Eds.) Voces y ecos de la violencia. Chile, El Salvador, México y Nicaragua. Santiago: CESOC.

Christodoulidis, E. (2000). Truth and reconciliation as risks. Social \& Legal Studies, 9, 179-204.

COMISIÓN NACIONAL SOBRE PRISIÓN POLÍtICA Y TORTURA (2004). Santiago: Ministerio del Interior.

Corporación NACIONAL DE REPARACIÓN y RECONCILIACIÓN (1996). Informe sobre calificación de víctimas de violaciones de derechos humanos y de la violencia política: Santiago: Ministerio del Interior.

Derrida, J. (1989). La estructura y la diferencia. Barcelona: Anthropos.

Doxtader, E. (2003). Reconciliation-a rhetorical conception. Quarterly journal of speech, 89, 267-292.

Eмa, J. (2006). Del sujeto a la agencia. Un análisis psicosocial de la acción política. Tesis de doctorado no publicada, Universidad Complutense de Madrid.

Fernández, R. (2005). Memoria y conmemoración del golpe de estado de 1973 en Chile: La marcha del 11 de septiembre desde una perspectiva auto etnográfica. Tesis de Maestría no publicada, ARCIS-UAB.

Foucault, M. (1992). Microfísica del poder. Madrid: La Piqueta.

Foucault, M. (1997). Vigilar y castigar. El nacimiento de la prisión. México: Siglo XXI.

Gadamer, H. (1991). Verdad y método. Salamanca: Sígueme.

Govier, T. \& Verwoerd, W. (2002). Trust and the problem of national reconciliation. Philosophy of the Social Sciences, 32, 178-205.

Grupo de trabajo Queer. (2005). El eje del mal es heterosexual. Madrid: Traficantes de sueños.

Humphrey, M. (2005). Reconciliation and the therapeutic state. Journal of intercultural studies, 26, 203-220.

Ilas (1991). Derechos Humanos: Todo es según el dolor con que se mira. Santiago: ILAS. 
Ilas (1994). Psicología y violencia politica en América Latina. Santiago: CESOC.

Informe Comisión Nacional de Verdad y Reconciliación (1991). Santiago: Corporación Nacional de Reparación y Reconciliación.

Joignant, A. (2007). Un dia distinto: Memorias festivas y batallas conmemorativas en torno al 11 de septiembre en Chile 1974-2006. Santiago: Universitaria.

Juricic, F. y Reyes, M.J. (2000). El si-no de la reconciliación nacional. Representaciones sociales de la reconciliación nacional en los jóvenes. Santiago: Arzobispado de Santiago, Fundación Documentación y Archivo de la Vicaría de la Solidaridad.

KeIlson, H. (1979). Sequential traumatization in children. Jerusalem: The magnes press, the Hebrew University.

LACAN, J. (1977). The four fundamental concepts of psychoanalysis. Hardmondsworth: Penguin.

Laclau, E. y Mouffe, Ch. (1985). Hegemonía y estrategia socialista. Hacia una radicalización de la democracia. Madrid: Siglo XXI.

LiRA, E. (1997). Transiciones políticas: ¿Verdad y memoria o reconciliación y desmemoria? En Lira, E. y Piper, I. (Eds.) Subjetividad y politica: diálogos en América Latina (pp. 129-154). Santiago: CESOC.

Lira, E. y Loveman, B. (1999a). La vía chilena de la reconciliación. Revista Mensaje, 48, 481-490.

Lira, E. y Loveman, B. (1999b). Las suaves cenizas del olvido. Via chilena de reconciliación politica. Santiago: LOM- DIBAM.

Lira, E. y Morales, G. (Eds) (2005). Derechos humanos y reparación: una discusión pendiente. Santiago: CESOC.

Lira, E. y Piper, I. (I996). Reparación, derechos humanos y salud mental. Santiago: CESOC.

Lira, E. y Piper, I. (Eds) (1997). Subjetividad y politica: diálogos en América Latina. Santiago: CESOC.

Martín-Baró, I. (1990). Psicología social de la guerra. San Salvador: UCA Editores.

Melucci, A. (I996). Challenging codes: Collective action in the information age. Cambridge: Cambridge University Press.

Mohanty, Сн. (2003). Feminism without borders: Decolonizing theory, practicing solidarity. Duke University Press.

Mouffe, Ch. (1992). Feminism, citizenship and radical democratic politics. In J. Butler \& J. Scott (Eds.). Feminist theorize the political. New York: Routledge.

Mouffe, Ch. (1999). El retorno de lo político. Barcelona: Paidós.

Moulian, T. (1997). Chile actual: Anatomía de un mito. Santiago: LOM. 
Piper, I. (2005). Obstinaciones de la memoria: La dictadura militar chilena en las tramas del recuerdo. Tesis de doctorado no publicada, Universidad Autónoma de Barcelona.

Pupavac, V. (2004). War on the couch. European journal of social theory, 7, 149-170.

Reicher, S. (2004). The context of social identity: Domination, resistance, and change. Political psychology, 25, 921-945.

ReYes, M. (2003). Entre la reconciliación y la convivencia. Un análisis de las narraciones cotidianas en el contexto chileno. Tesis de maestría no publicada, Universidad Autónoma de Barcelona.

SchaAp, A. (2004). Political reconciliation. Through a struggle for recognition? Social legal studies, 13, 523-540.

SpIVAK, G. (1999). Los estudios subalternos: La deconstrucción de la historiografía. En N. Carbonell \& M. Torras (Comp.). Feminismos literarios. Madrid: Arco/libros.

Staub, E. (2006). Reconciliation after genocide, mass killing, or intractable conflict: Understanding the roots of violence, psychological recovery, and steps toward a general theory. Political psychology, 27, 867-894.

Wittgenstein, L. (1987). Tractatus logico-philosophicus. Madrid: Alianza.

Fecha de Recepción de artículo: 15 de junio 2009

Fecha de Aceptación de artículo: 14 de septiembre 2009 